Sharif University of Technology
Scientia Iranica
SCIENTIA
I RAN I C A

\title{
Dynamic network pricing to contain urban air pollution in stochastic environment
}

\author{
H. Poorzahedy ${ }^{\mathrm{a}, *}$, B. Aghababazadeh ${ }^{\mathrm{a}}$ and A. Babazadeh ${ }^{\mathrm{b}}$ \\ a. Institute for Transportation Studies and Research, Department of Civil Engineering, Sharif University of Technology (SUT), \\ Tehran, 14588 , Iran. \\ b. School of Civil Engineering, University of Tehran, Tehran, Iran.
}

Received 3 June 2015; received in revised form 7 September 2015; accepted 16 February 2016

\author{
KEYWORDS \\ Demand management; \\ Network pricing; \\ Air pollution; \\ Markovian decision; \\ Resilient cities; \\ Cordon pricing; \\ Park-and-ride.
}

\begin{abstract}
Network pricing is an effective transportation demand management scheme to reduce traffic and control air pollution, particularly in CBDs. In this study, congested area cordon entry and Park-and-Ride $(\mathrm{P} / \mathrm{R})$ facility use are priced for automobiles. Increase in these prices may reduce private auto demand by impelling some of the auto passengers to use public transport from the origin of their trips, or encouraging them to park their cars at the $\mathrm{P} / \mathrm{R}$ facilities and use buses, or pay the entrance fee and drive inside the cordon. A Markov decision process has been devised to find an optimal policy for pricing the $P / R$ facilities and cordon entry in a city within a variable demand context. This process is sensitive to weather condition (more favorable atmospheric condition allows lower prices). It leads to a balance between the costs of pollution hazards to the public at large on one side and the cost imposed upon auto drivers to take the next best decisions and their travel times and costs on the other side, thus giving a resilient character to the city. The model has been applied to the network of a large urban area and the results are analyzed. Suggestions for further research end the discussion.
\end{abstract}

(C) 2016 Sharif University of Technology. All rights reserved.

\section{Introduction}

The race between supply and demand of private transportation has caused many problems, particularly in urban areas. These problems include congestion, pollution, and excessive consumption of the limited resources and energy, which have pushed large metropolitan areas into a fierce environmental degradation. It is now well-known that to close the gap between the supply and demand, one solution method is to manage the demand.

Several policies have been devised for demand management. They include granting certain privileges

\footnotetext{
* Corresponding author. Tel.: +982161112176 E-mail addresses: porzahed@sharif.edu (H. Poorzahedy); babak.babazadeh@gmail.com (B. Aghababazadeh); ababazadeh@ut.ac.ir (A.Babazadeh)
}

to some sector(s) of demand, imposition of prohibitive or regulatory ordinances, and increase in the cost of using certain facilities like parking in congested areas, tolls on the use of highways, and taxes on car ownership and use.

Some social costs of automobiles may be easily levied upon their owners/users through various taxes and tolls (e.g., cost of land or maintenance of pavements). However, many other costs are hard to transfer to their producers (e.g., air pollution, noise pollution, loss of amenities, and delays in traffic). Taxing general public, or auto drivers, uniformly for these costs is unjustifiable and unproductive, as the cost producers do not receive the proper signal to correct themselves [1]. Thus, network pricing becomes a tool for the management of transportation systems.

Network pricing aims for several objectives, for 
example reducing congestion (as in Singapore and Hong Kong), pollution (as in Stuttgart and Stockholm), and collection of revenues to invest in the network (as in Bergen and Oslo) [2]. There is appreciable literature on pricing links (bridges, tunnels, highways, etc.), zones, and transportation facilities (parking, etc.), but little work has been reported in the area of simultaneous cordon and park-and-ride pricing, to reduce congestion and air pollution problems. This paper presents the results of an effort in this area in a new way.

The proposed procedure starts by identifying and defining the congestion or pollution plagued area in order to price all vehicles (except the authorized) crossing its boundary based on some pricing method. The parkand-ride lots, or facilities, are given in the study area, the prices of which jointly with the cordon prices are sought in a stochastic Markovian environment of air quality in the city so as to maximize the net benefit of the system under study. Pricing is an interventional mechanism; however, such intervention is considered warranted when externalities threaten the public at large or the environment. Due to the stochastic nature of demand and environment, this pricing becomes stochastic.

The need for this study stems from the need to manage congestion, pollution, and other unwanted outcomes of private car transportation. This is magnified by the need to have an apparatus for governance in large cities to contain the negative effects of auto trips where and when it is necessary. The proposed model is a means to give large cities the resiliency properties they need in extreme situations [3,4].

In Section 2, a review of the literature in this area is presented, followed by a definition of the problem in Sections 3. The problem is formulated as a Markov Decision Process in Section 4, where the reward matrix components, and the transition probability matrix and the effect of the atmospheric conditions upon it are defined. Section 5 is devoted to the application of the model to the large City of Shiraz, Iran. Section 6 will shed light on the performance of the model. Optimal policies are discussed in Sections 7. Finally, Section 8 summarizes and concludes the paper and suggests possible future research directions.

\section{A review of the literature}

In the review of the literature, we try to be selective of papers that specifically deal with pricing automobiles for air pollution control, and not pricing transportation networks in general that cover a wide range of objectives. Amirgholy et al. [5], based on the review of over 100 references, discuss the matter quite extensively under wide ranges of topics. Tsekeris and $\operatorname{Vo} \beta[6]$ also present a rather recent review of road pricing studies and research, covering over 400 references of which few papers have focused on the air quality and car emission aspects of the network pricing. Khazzoom [7], Shefer [8], Otterström [9], Chin [10], Joumard et al. [11], Proost and Van Dender [12], Beevers and Carslaw [13], Mitchell [14], Mitchell et al. [15], and Schuitema et al. [16] are among the authors who have dealt with the air quality.

A recent work on congestion pricing to control emission is presented by Dai et al. [17] who emphasize the real threat of air pollution in Chinese cities. They present a bi-level model to trade off network efficiency against improved air quality. Their model considers two modes (car and bus) and they apply it on a small hypothetical network.

Vehicular emission is proportional to vehiclekilometers of travel (vkt). Lyons et al. [18] show a strong relationship between (vkt) and urban land area. They present a model for estimating urban vehicular pollution by using this relationship and incorporating simple meteorological forces such as average annual wind speed and mixing height.

Leeves and Herbert [19] use a non-linear discrete time model to analyze the damage to the environment by the rate of change of the pollution stock. Their model links the economic growth to the health of environment and pollution flows affect the stock of natural resources in it. They discuss pollution control strategies and show that investing in the pollution control strategies, which employ production technologies that reduce pollution, is more effective than the strategies that deal with the effects of the pollution flow into the environment.

A review of the methods of road pricing is done by de Palma and Lindsey [20], including pricing lanes, facilities, cordon, and zones based on distances time (flat, time-of-day, responsive), and vehicle characteristics (type, weight, number of axles). They note that pricing technologies are also numerous: roadside detection, dedicated short-range communications, and in-vehicle technologies that rely on satellite or cellular networks. They provide clues for the choice of appropriate methods and technologies.

One popular, practical, and effective way of controlling car flow in certain areas is cordon pricing. This method, which is the second best method for controlling traffic congestion and the related externalities, particularly in mono-centric cities, forms a significant body of the literature. May et al. [21], Sumalee [22,23], Zhang and Yang [24], Mun et al. [25,26], and $\mathrm{Ho}$ et al. [27] analyze and discuss aspects of this method.

Amirgholy et al. [5] show the popularity and effectiveness of cordon pricing in targeting specific problems, including air pollution. Their conclusions include the following: (a) Actual implementation of 
this pricing method verified that emission reduction (leading to environmental and health improvements) was a byproduct of the implemented scheme [28]; (b) Public transportation alone could not reduce the network congestion appreciably even in its ideal condition [29]; (c) Paying for the roads based on the level of use is technically successful, and tends to gain public acceptance when introduced. Moreover, it contributes positively to the environment [30]. They also discuss long/short-term pricing effects, and pricing models' methodology, limitations, and conclusions.

In our review of the literature, we have not seen any research that considers modeling the interaction of the operator-user-environment at a real-size network level in order to govern network use to endure certain environmental quality. The model of this paper aims to help sustain urban air quality where this problem is acute by employing a cordon pricing scheme, which encourages car drivers to use public transport from their origins, or by switching to public transport en-route at a park-and-ride facility. The operator determines the optimal price to minimize the long-run total system cost dynamically based on the current level of the ambient air pollution and the stochastic variations of the environment. This total system outcome includes the transportation time and monetary cost, the cost to the car drivers in choosing their next best modes, and the benefit of reduction in the pollution cost. Such interactive control should be an essential part of the management of any resilient city.

\section{Problem definition}

A city is potentially faced with air pollution problem, basically caused by mobile sources. The operator of the city network considers zoning the city for pricing private car drivers entering these zones to encourage them to use public transportation modes. There are several park-and-ride facilities at the zone boundaries, or at their proximity, which are also priced differently. The prices are designed in increments which may be chosen by the operator based on the level of pollution in the city.

Pollution is detected by an index related to mobile sources, which is chosen to be CO (Carbon MonoOxide) level in this study. Depending on the weather condition (wind speed, precipitation level, etc.), CO level changes, so price levels of entering the cordon and parking at the park-and-ride facilities for tomorrow are determined based on a long-run trend of weather condition for future (using past trends) and the prevalent $\mathrm{CO}$ level in the city, determined by a Lidar (light detection and ranging) and related technologies. The public are informed about these prices the day/night before tomorrow through suitable means of communication (radio, television, variable signs at suitable places, etc.).

The objective of the operator of the system is, by observing today's CO level and by having longrun weather forecast, to choose tomorrow's price levels such that the total cost of pollution and congestion in the city is minimized in the long run. Figure 1

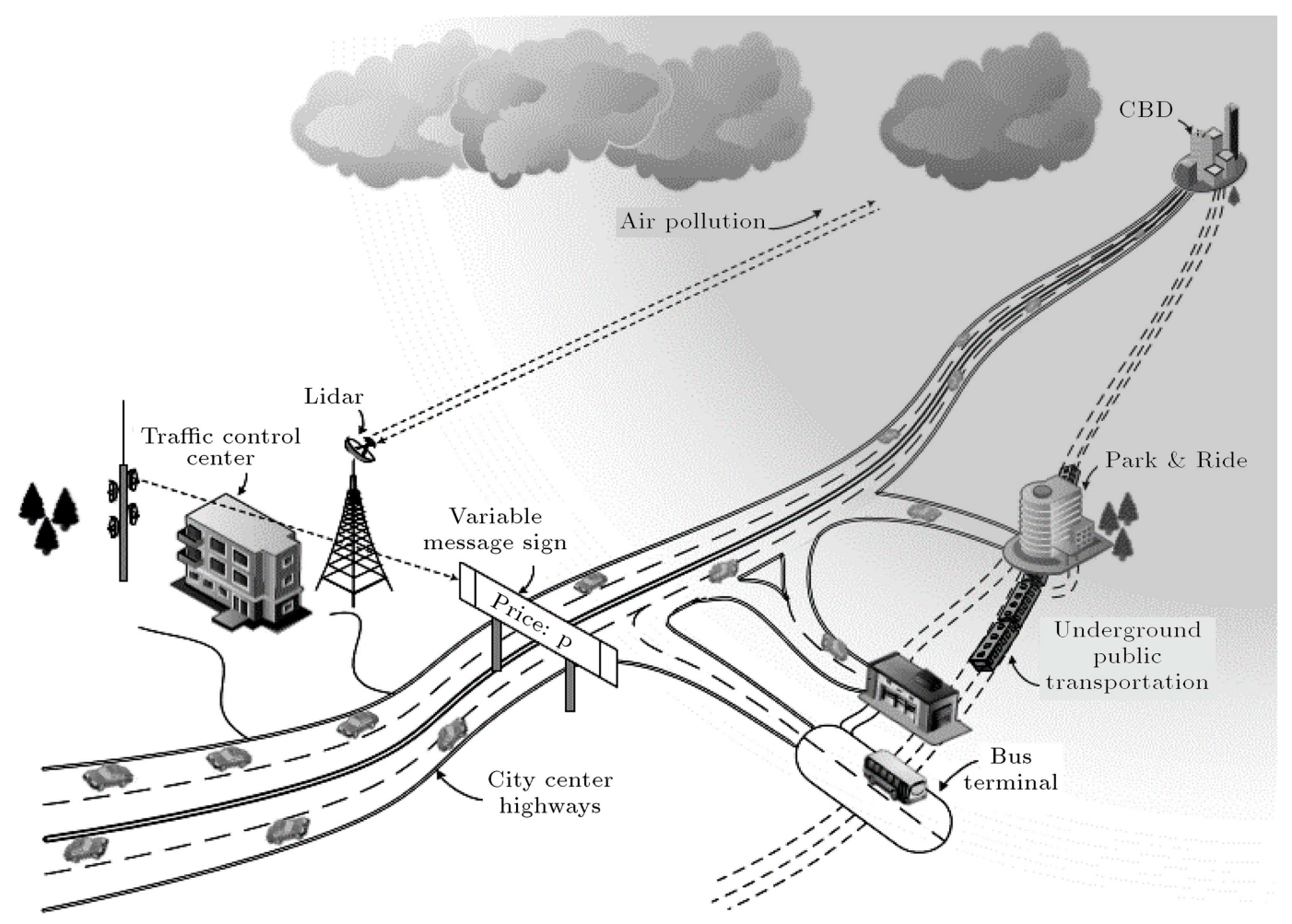

Figure 1. A pictorial view of the decision process in the problem. 
shows a pictorial view of the decision and the air quality process.

This study is concerned with short-range decisions of the users (one to three years, which includes mode changes). However, we will also talk about long-run Markov process where time increments are measured in days. Hence, it is important to note that these two ranges for the two processes are congruent in the sense that there are quite a high number of days in a year. The readers may find long-term user decisions and effects in other papers, for example Amirgholy et al. [5].

\section{The problem formulation}

The problem is formulated as a Markov decisionmaking system and solved for the decision variables. The following sections set the stage for the problem definition and formulation.

\subsection{The Markov process with reward}

Let $X=\left\{X_{n}, n \in N\right\}$ be a Markov chain with state space, $E$, and $|E|=m$. Suppose that transition from state $i$ to state $j, i$ - where $j \in E$ - occurs with a probability $p(i, j)$, which is followed by a reward $r(i, j)$ (positive or negative). Thus, by virtue of the nature of $X$, rewards $R$ will possess a stochastic nature.

Let $v^{n}(i)$ be the expected value of the reward after $n$ transitions of the system; then:

$$
v^{n}(i)=\sum_{j=1}^{m} p(i, j)\left[r(i, j)+v^{n-1}(j)\right] .
$$

Let $q(i)=\sum_{j=1}^{m} p(i, j) \cdot r(i, j)$. Z-transform analysis of Eq. (1) reveals that (see [31]) for large $n$ 's:

$$
v^{n}(i)=n g(i)+v(i), \quad i \in E,
$$

where $v(i)$ is the asymptotic value of $v^{n}(i)$, when $n \rightarrow$ $\infty$, and:

$$
g(i)=\sum_{j=1}^{m} s(i, j) q(j), \quad i \in E
$$

and where the stochastic matrix $S$ has elements $s(i, j)$ whose $i$ th row is the limiting probability of the system being in state $j \in E$, starting from state $i \in E$. Then, $g(i)$ may be interpreted as the expected value of the reward of the system, given that it started from state $i$ and has undergone many iterations, or the revenue of the $i$ th state, or the asymptote of $v^{n}(i)$.

If the system is completely ergodic, all rows of $S$ become the same, and all states would have the same revenue, say $g(i)=g$ for all $i$ 's:

$$
g=\sum_{j=1}^{m} \Pi(j) q(j)
$$

where $\Pi(j)$ is the limiting probability of the system to be in state $j$ and for large $n$, we may write Eq. (2) as:

$$
v^{n}(i)=n g+v(i), \quad i \in E .
$$

Suppose, now, that alternatives $k=1,2, \ldots, K$ are available for choice in each state $i, i \in E$. For each $k$, the transition matrix, $P^{k}$, and the corresponding reward matrix, $R^{k}$, are known. $p^{k}(i, j)$ and $r^{k}(i, j)$ are, respectively, the probability and reward of moving from state $i$ to state $j$ when decision $k$ is taken. The operator of the system is interested in knowing the best decision to take, in each stage (day) $n$ and in each state $i$, so as to maximize the total reward during the time interval $[0, n]$. The set of all decisions for all $i$ 's and all $n$ 's, $\left\{d_{i}^{n}: i \in E\right.$ and $\left.n=0,1,2, \ldots\right\}$, is called a policy. $d_{i}^{n}$ indicates the alternative (number) to choose in stage $n$ when the system is found in state $i$. Therefore, the problem is to find $\left\{d_{i}^{n}\right\}$ such that:

$$
\begin{aligned}
v^{n+1}(i) & =\max _{k} \sum_{j=1}^{m} p^{k}(i, j)\left[r^{k}(i, j)+v^{n}(j)\right], \\
& =\max _{k}\left[q^{k}(i)+\sum_{j=1}^{m} p^{k}(i, j) \cdot v^{n}(j)\right], \\
i & \in E, \quad n=0,1,2, \ldots,
\end{aligned}
$$

where $q^{k}(i)=\sum_{j=1}^{m} p^{k}(i, j), r^{k}(i, j)$ is associated with the respective $P^{k}$ and $R^{k}$ matrices.

Given policy $\left\{d_{i}^{n}=k\right\}$ associated with known $P^{k}$ and $R^{k}$, for a limiting behavior of the system $(n$, large), Eqs. (1) and (5) yield:

$$
g=q^{k}(i)+\sum_{j=1}^{m} p^{k}(i, j)[v(j)-v(i)], \quad i=1,2, \ldots, m
$$

This is a system of $m+1$ unknowns and $m$ linear equations, which may be solved for $g$ and the relative values of $v(i)$ 's, assuming, e.g. $v(m)=0$. Having found the relative values of $v(i)^{\prime} s$ and $g$, one may now find the optimal decision for state $i$ and time (stage) $n+1$, using Eq. (6) and $v^{n}(i)=n g+v(i)$ for large $n$, by maximizing the right-hand side of the following equations over $k$ :

$$
g+v(i)=\max _{k}\left\{q^{k}(i)+\sum_{j=1}^{m} p^{k}(i, j) \cdot v(j)\right\}, \quad i \in E .
$$

Howard [31] proves that one may stop calculation if the resulting policy is the same as the one which was the input for Eq. (7), and hence this is the optimal policy yielding maximum average daily reward in the limit. Otherwise, the process is reiterated by inputting the new policy into Eq. (7). The Howard [31] policy iteration method may be stated as follows: 


\section{Procedure HP:}

- Step 0. Initialization: $P$ and $R$ are known for various $k$ 's. Choose an initial policy $d$;

- Step 1. Value determination: Find $P$ and $R$ corresponding to the policy $d$, and compute $q(i)$ 's by:

$$
q(i)=\sum_{j=1}^{m} p(i, j) \cdot r(i, j), \quad i \in E .
$$

Then, find the relative values of $v(i)$ 's and $g$ by:

$$
g+v(i)=q(i)+\sum_{j=1}^{m} p(i, j) \cdot v(j)
$$

using $v(m)=0$.

- Step 2. Policy improvement: Using $v(i)$ 's, $i \in E$, of the previous policy, $d$, find the decision $k^{*}$ which maximizes:

$$
q^{k}(i)+\sum_{j=1}^{m} p^{k}(i, j) \cdot v(j)
$$

$d^{*}$ is the new policy.

- Step 3. Convergence criterion: If $d^{*}=d$, STOP; $d^{*}$ is the optimal policy. Otherwise, set $d=d^{*}$ and go to Step 1

It can be shown that the value of $g$ in any iteration becomes greater than that of the previous one and when the procedure stops, $d^{*}$ has the maximum $g$ and average daily reward. Since the total policies are limited in number, the procedure stops in a limited, and in fact very low, number of iterations.

\subsection{The reward matrix}

Consider the case where the O/D demands are fixed and short-run (one to several years) results are of importance. Assume, further, that the short-run decision is only mode change. Then, the reward accrued by any air-pollution control decision $k$ is the sum of two outcomes: (a) the benefit of the positive air quality change of state from $i$ to $j, i, j \in E$ (determined by the ambient air CO level), and (b) the net benefit resulting from a lower transportation cost (travel time). The decision is related to the change of tolls in private automobiles entering a zone. This would affect the drivers' decisions on the mode choice. When the cost to the environment is increasing because of the stagnant air in the city, increasing the tolls will push those drivers toward using a public mode completely or partially (by parking at a park-and-ride transit station to use public transportation to final destinations).

The following discussions describe the problem environment and its sensitivity to the operator's decisions on the prices more extensively. The model presented below is one workable model for illustrative purposes, constructed to operate with an existing extensive and comprehensive transportation model for the case under study. Thus, some of its components may be altered according to modeling needs and approaches.

\subsubsection{Mode choice models}

The mode choice model of this study is of a multinomial logit type, as shown below:

$$
P r_{k s}^{p m}=\frac{e^{U_{k s}^{p m}}}{\sum_{n \in M} e^{U_{r s}^{p m}}}, \quad \forall m \in M, \quad \text { and } \quad \forall(k, s) \in P,
$$

where $P r_{k s}^{p m}$ is the probability of choosing mode $m$ for a trip with purpose $p$ from origin $k$ to destination $s$, which possesses a utility $U_{k s}^{p m} . M$ is the set of (major) available modes (which may be $\mathrm{O} / \mathrm{D}$-specific), and $P$ is the set of $\mathrm{O} / \mathrm{D}$ (origin-destination) pairs. The utility function $U_{k s}^{p m}$ is a function of the independent variables/characteristics of the modes (e.g., travel time), passengers (e.g., car-ownership), and trip purpose (e.g., work).

Tolls on private cars in crossing a restricted zone boundary would negatively affect the utility of this mode. Without loss of generality, we assume that we only price auto trips originating from an origin (O) outside the restricted zone(s) and destinations (D) inside these zones. Extensive experiments have shown that auto drivers with $\mathrm{O}$ and $\mathrm{D}$ outside the cordon and their shortest paths crossing cordon boundaries prefer to either use car and change path so as not to cross the cordon or use public transportation from the beginning. Thus, by computing the new shortest path travel times outside the priced zone for the cars and the cost of using other modes, new mode shares are computed for these drivers. Then, the estimated reduced auto passengers are diverted to public transit modes, or park-and-ride system.

The portion of the total auto passengers from origin $k$ to destination $s$ for trip purpose $p, w_{k s}^{p}$ who are willing to pay certain toll is assumed to be an inverse-s function of the toll, as follows:

$$
w_{k s}^{p}=\exp \left[-a\left(\frac{\tau}{D_{k s}}\right)^{b}\right], \quad a, b>0
$$

where $\tau$ is the toll to enter the restricted zone, $D_{k s}$ is the shortest network distance from $k$ to $s$, and $a$ and $b$ are two parameters of the function.

Assume, now, that $y_{k s}^{p}$ is portion of the auto demand planning to change mode and choose public transit or park-and-ride and $\left(1-y_{k s}^{p}\right)$ choose taxi (which, in our case, is allowed to enter the restricted zone free of charge) according to the following s-shaped diversion curve:

$$
y_{k s}^{p}=\exp \left[-c\left(\frac{\tau}{D_{k s}}\right)^{d}\right], \quad c>0, \quad d<0
$$


where $c$ and $d$ are two parameters of the function. (These are two suitable functional forms observed to behave well and fit best the data obtained in a real case, as reported in ITSR [32].)

Thus, increasing $\tau$ per unit distance $\left(D_{k s}\right)$ decreases $w_{k s}^{p}$, increases $\left(1-w_{k s}^{p}\right)$, increases $y_{k s}^{p}$ as well as $y_{k s}^{p}\left(1-w_{k s}^{p}\right)$, and most likely increases $\left(1-y_{k s}^{p}\right)\left(1-w_{k s}^{p}\right)$, the latter two being the share of transit and parkand-ride, and the share of taxi from the diverted auto demand, respectively (see Figure 5(a) and (b) for pictorial views of these functions.)

The portion of the diverted auto demand for a purpose $p$, which is absorbed by public transit or parkand-ride system, decides to use either mode based on the minimum of the transit time from $k$ to $s, t_{k s}^{b}$, or equivalent park-and-ride time, $t_{k s}^{P R}\left(=t_{k, P / R}^{a}+t_{P / R . s}^{b}+\right.$ $\left.\beta c_{P / R}\right)$. Other diversions are feasible, but a $0 / 1$ choice is used here for simplicity in building a demonstration model. In the above expression, $P / R$ represents the nearest park-and-ride facility on the way from $k$ to $s, t_{k, P / R}^{a}$ is the shortest auto travel time from origin $k$ to the nearest park-and-ride facility, $t_{P / R, s}^{b}$ is the shortest transit time from the park-and-ride facility to destination $s$, and $c_{P / R}$ is the parking and transit fare cost which is translated into equivalent travel time by the conversion factor, $\beta$ (inverse of the value of unit travel time).

\subsubsection{Auto operating cost}

Auto operating cost is comprised of costs of auto investment, operation, maintenance, and repair, as well as accident/insurance cost. Let $\bar{c}$ represent an average of such cost in money units per car-kilometer. Thus, auto operation cost per hour under decision $k, C_{o p a}^{k}$, may be calculated as follows:

$$
C_{o p a}^{k}=\bar{c}\left(X^{\prime 1}-X^{\prime k}\right),
$$

where $X^{\prime} k$ is the auto-kilometer traveled in the network per hour (of, e.g. morning peak) under decision $k$, and $k=1$ is the do-nothing alternative.

\subsubsection{Equivalent travel time monetary cost}

Let $c_{t}$ be the value of one person-hour travel time and $C_{t_{a}}^{k}$ be the equivalent monetary cost of total non-transit travel time under decision $k$. Then:

$$
C_{t_{a}}^{k}=c_{t}\left(Y^{1}-Y^{k}\right),
$$

where $Y^{k}$ is the passenger-hour of all vehicles, except bus, under decision $k$ and $k=1$ is the do-nothing alternative:

$$
Y^{k}=\sum_{\substack{m \in M \\ m \neq b u s}} \alpha^{m} Y^{m k}
$$

where $\alpha^{m}$ is the average occupancy rate (passenger per

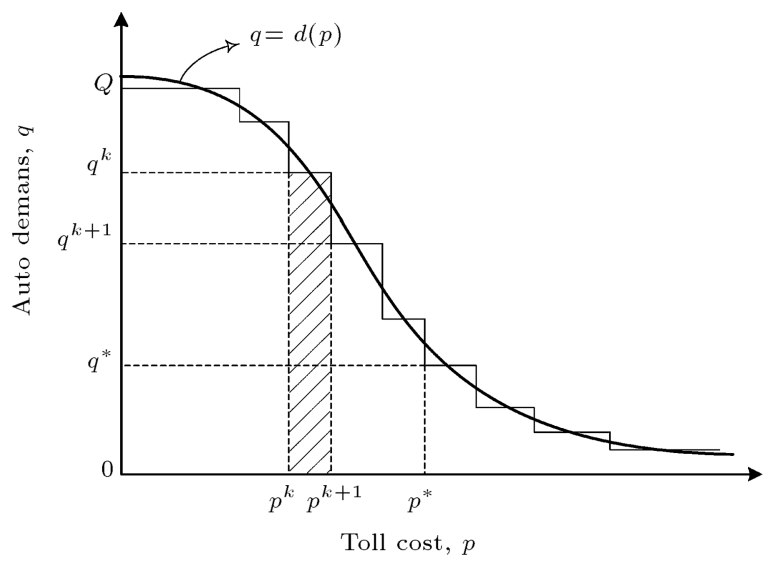

Figure 2. Theoretical and experimental estimates of the imputed cost upon the car drivers by toll imposition.

vehicle) of mode $m$ and $Y^{m k}$ is the travel time of mode $m$ under decision $k$.

Let $\bar{Y}^{k}$ be defined as the public transit (bus) total travel time (in passenger-hours) under decision $k$; then, the equivalent monetary cost of the public transit travel time spent in the network, $C_{t_{b}}^{k}$, may be written as:

$$
C_{t_{a}}^{k}=c_{t}\left(\bar{Y}^{1}-\bar{Y}^{k}\right) .
$$

It is expected that, in general, $Y^{1}>Y^{k}$ and $\bar{Y}^{1}<\bar{Y}^{k}$.

\subsubsection{Cost of reduction in car passengers' utilities}

Let $Q$ be the maximum number of private cars for an O/D pair whose demand function is shown in Figure 2. Then, an estimate of the cost of the car passengers to change car to an inferior mode, when $(p, q)$ changes to a new equilibrium $\left(p^{*}, q^{*}\right)$, is the reduction in Consumers' Surplus (CS) as follows:

$$
\Delta C_{c s}=\int_{0}^{p^{*}} q \cdot d p=\int_{0}^{p^{*}} d(p) d p .
$$

This is because at price $p, q$ passengers were willing to drive their cars. When price is increased to $p+$ $d p$, demand of automobiles decreases to $q-d q$ and $d q$ of demand is diverted to their second best modes. Thus, $d q$ passengers who were willing to pay price $p$ to use their cars are now diverted to get off their cars by the price increase from $p$ to $p+d p$. An approximate measure of $\Delta C_{c s}$ may be experimentally found by our transportation model (described below) according to the following relation, as shown in Figure 2:

$$
\begin{aligned}
\Delta C_{c s}^{k^{*}} & =\sum_{k=1}^{k^{*}}(1 / 2)\left(q^{k}+q^{k+1}\right)\left(p^{k}-p^{k-1}\right), \\
p^{0} & =0,
\end{aligned}
$$

where $q^{k}$ is the demand for private car (in this study, from an origin to a destination inside the cordon) when the price to enter the cordon is $p^{k}$ under decision $k$. 


\subsection{The transition probability matrix}

There are three factors affecting the Markov transition probabilities, each having a stochastic effect. They are: (a) ambient air pollution (CO) level as a result of (basically private) vehicle emissions; (b) atmospheric turbulences (winds, precipitations, etc.); and (c) the operator's decision (pricing automobiles entering the restricted zones).

At a regional level, there is a recursive equation postulated between the pollution concentration, $P$, pollutant emissions, $E$, and atmospheric phenomena, $A$, as follows [33]:

$$
P(n)=f(P(n-1), E(n), A(n)),
$$

where $n$ represents day $n$. That is, the concentration of the pollution level in day, $n$, is only dependent on that of the previous day (a Markov property) as well as the pollution emitted by automobiles (presumably, under the influence of the operator's decision) in this day, along with the decision of the nature (the atmosphere) on the wind speed and precipitations (as well as temperature, humidity, etc.).

If there is no weather influence upon the ambient air, any state (of air pollution) will either remain as it is or turn into another worse condition by the car emissions. The transition probabilities of moving the state of the system from $i$ to $j, j \geq i$, under decision $k, p^{k}(i, j)$, may be estimated by knowing the lifetime (duration) distribution of any state of the system. One suitable distribution for lifetime of state, $T_{i}$, is negative exponential, as follows:

$$
f_{T_{i}}(t)=\theta_{i} e^{-\theta_{i} t}, \quad t \geq 0, \quad \theta_{i}>0, \quad i \in E .
$$

Let $E=\{(1=$ healthy $),(2=$ tolerable $),(3=$ Harmful $)\}$ be the state space of the ambient air quality. We are interested in the probability of the change of state within a given time period, e.g. a $24 \mathrm{hr}$ day (end of day to end of day).

In a meso-scale, total automobile emission of pollutants is a function of total vehicle-kilometers per hour [18]. For simplicity, vehicles are divided into two public and private categories and for their overwhelming roles in the travel market, buses and automobiles are taken as the representatives of these two categories, respectively. Thus, we concentrate on bus-km and car-km (or their equivalents). For $X(n)$ as the (equivalent-) car-km and $X^{\prime}(n)$ as the (equivalent-) bus-km traveled in day $n$, one may write the parameters of the transition probability distributions as a function of these two influencing variables as follows:

$$
\theta_{i}(n-1, n)=G_{i}\left[X(n), X^{\prime}(n)\right],
$$

where $\theta_{i}(n-1, n)$ is the parameter of lifetime probability function of state (air quality level) $i$ of the system, influencing its change from (end of) day $n-1$ to (end of) day $n$, which is a function of the vehicle-kilometers traveled in day $n, X(n)$, and $X^{\prime}(n)$.

Suppose that the change in bus-kilometers traveled is nearly constant and is of little importance in the measurement of the quality of ambient air. After all, the decision-makers are to shift the demand from cars to buses (or, in general, public transport), which is presumably friendlier to the environment than cars. So, Eq. (23) is simplified as follows:

$$
\theta_{i}(n-1, n)=G_{i}[X(n)]
$$

or, in easier notations, as:

$$
\theta_{i}=G_{i}(X)
$$

As a first-degree approximation, it is assumed that for the three-state case under consideration:

$$
\theta_{i}=a_{i} X+b_{i}, \quad i=1,2,
$$

where $a_{i}$ and $b_{i}$ are the parameters of the model for state $i \in E, i=1$ and 2. Then, from Eqs. (22) and (26), we have:

$$
f_{T_{i}}(t)=\left(a_{i} X+b_{i}\right) e^{-\left(a_{i} X+b_{i}\right) t}, \quad t \geq 0 .
$$

It is expected to have $a_{i}>0$ and $\theta_{i}=a_{i} x+b_{i}>0$ for $x>0$. Thus, for this case (of traffic influence alone), one may write (see Appendix A):

$$
\begin{aligned}
p(1,1)= & e^{-\left(a_{1} x+b_{1}\right)}, \\
p(1,2)= & \frac{a_{1} X+b_{1}}{\left(a_{2}-a_{1}\right) X+\left(b_{2}-b_{1}\right)} \\
& {\left[e^{-\left(a_{1} X+b_{1}\right)}-e^{-\left(a_{2} X+b_{2}\right)}\right], } \\
p(1,3)= & 1-p(1,1)-p(1,2), \\
p(2,2)= & e^{-\left(a_{2} X+b_{2}\right)}, \\
p(2,3)= & 1-e^{-\left(a_{2} X+b_{2}\right)}, \\
p(3,3)= & 1 .
\end{aligned}
$$

Note that $p(i, j)$ 's are functions of $X$, which is itself a function of the operator's decision $k=1$ to $K$. Given $k, X(k)$ would be known, and so would be $p^{k}(i, j)$ 's.

Atmospheric phenomena (winds, rain, snow, etc.) are very effective factors in ambient air quality. The complex cause-and-effect relationships among basically unknown variables and parameters governing the happenstance of these phenomena leave these incidents as stochastic processes. Let $w_{j}$ be the probability that an atmospheric event would improve the ambient air quality by $j-1$ states regardless of the traffic condition. 
Then, for a three-state problem, $w_{1}, w_{2}$, and $w_{3}$ may be envisaged as light, medium, and heavy atmospheric changes, and:

$$
\sum_{j=1}^{m} w_{j}=1
$$

Suppose, now, that $p(i, j)$ is the transition probability of going from state $i$ to state $j$ under the influence of the atmospheric incidents. Assuming independence of atmospheric changes and air quality, and prompt effect (in matters of few hours), as well as approximating this effect to happen at the beginning of each day, one may write:

$$
\begin{aligned}
P(1,1)= & p(1,1)\left(w_{1}+w_{2}+w_{3}\right)+p(1,2)\left(w_{2}+w_{3}\right) \\
& +p(1,3)\left(w_{3}\right), \\
P(1,2)= & p(1,2)\left(w_{1}\right)+p(1,3) w_{2}, \\
P(1,3)= & p(1,3) w_{1} \\
P(2,1)= & p(2,2)\left(w_{2}+w_{3}\right)+p(2,3)\left(w_{3}\right), \\
P(2,2)= & p(2,2)\left(w_{1}\right)+p(2,3)\left(w_{2}\right), \\
P(2,3)= & p(2,3)\left(w_{1}\right), \\
P(3,1)= & p(3,3)\left(w_{3}\right), \\
P(3,2)= & p(3,3)\left(w_{2}\right), \\
P(3,3)= & p(3,3)\left(w_{1}\right),
\end{aligned}
$$

where $p(i, j)$ 's are as given in Eq. (28).

Thus, the Transition Probabilities (TP) may be computed depending on the tolls levied upon the automobile users in entering the congested zone(s), which changes the composition of private/public traffic in the network. This process is administered as follows:

\section{Procedure TP:}

a. Choose prices for entering the congested zone(s) and parking at a park-and-ride facility $(k)$;

b. Assign the $\mathrm{O} / \mathrm{D}$ demand under price $k$ to the network according to procedure AS;

c. Compute the policy $k$ outcomes, including total car$\mathrm{km} x^{k}$, based on procedure OC;

d. Compute the parameters of the lifetime distribution function under price $k, \theta_{i}^{k}=a_{i} x^{k}+b_{i}, i=1,2, \ldots, 3$;

e. Compute the transition probabilities of state $i$ to state $j$ in the study zone(s) under price $k$ : $P^{k}(i, j)=f\left(\theta_{i}^{k}, \theta_{j}^{k}, w_{j}\right)$.

\section{Procedure AS:}

The traffic assignment routine is an integrated model built for the case under study in EMME/2 environment by the Institute for Transportation Studies and Research of Sharif University of Technology [34].

This model constitutes two parts: demand estimation and traffic assignment. The first part receives the independent variables at zonal level and performs the following tasks by trip purpose: trip production and attraction, trip distribution, and mode choice. To adapt this model for the problem at hand, the diversion models of Eq. (13) are employed to compute the remaining trips of each trip purpose to be made by automobiles. The diversion models of Eq. (14) compute the portion of the diverted auto demand that will be attracted by the transit mode, either directly from the origin of the trip or through the nearest $\mathrm{P} / \mathrm{R}$ facilities, whichever is less costly, as described in Section 4.2.1. The rest of the diverted auto trips are absorbed by taxis. This process prepares the $\mathrm{O} / \mathrm{D}$ demand by various available modes of travel in two forms of equivalent passenger car demands for the road network and passenger demand for the transit network.

Traffic assignment routines start by the transit assignment using Optimal Strategy algorithm [35]. This prepares the stage for the assignment of passenger cars according to multi-class user equilibrium [36,37]. The travel times are updated for the transit assignment and this procedure is re-iterated to convergence. The results (link volumes, travel time components, kilometers travelled, fuel consumed, emissions of $\mathrm{CO}$ and other pollutants, etc.) are summarized and reported in detail in 15 specifically designed tables.

\section{Procedure $O C$ :}

The outcomes of Procedure AS that are of particular importance in this study are non-transit passengerhour $\left(Y^{k}\right)$, transit passenger-hour $\left(\bar{Y}^{k}\right)$, passenger carkilometer $\left(X^{\prime k}\right)$, and liters of fuel consumed $\left(L^{k}\right)$, where $k$ represents the decision on price level. The first two quantities would give the equivalent monetary cost of travel times spent in the network (Eqs. (16) and (18)). The third quantity would be used in the computations of auto operating cost (Eq. (15)), and the fourth may be transformed into its monetary value. Moreover, increasing the travel cost for car drivers would make them worse off by reduction in consumers' surplus (Eq. (20)). Hence, this cost should also be added to the previous ones to account for the worse conditions of the car drivers as a result of our actions. The benefit accrued by our decisions would be the reduction of the emitted pollutants (here, $\mathrm{CO}$ ) that is expected to outweigh the aforementioned costs.

Appendix B presents an overall view of the model in three parts. It shows how different modules interact. Figure B.1 in part (a) of Appendix B shows the 
flowchart for the Markovian decision-making procedure. It uses two important inputs: the Reward Matrix (the output of Figure B.2 process in part (b) of the same appendix) and the Transition Probabilities for the specified toll level. Figure B.2 contains Procedure AS, which computes the flows of different modes of transportation for any given toll level, and Procedure OC, which acts on this information to compute the reward matrix. The transition probabilities are computed in Figure B.3 of part (c) of this appendix through Procedure TP. The input to the flowchart in part (c) comes also from part (b) in the form of the (equivalent) car-kilometer travelled.

\section{Case study}

The case under study is the City of Shiraz with a population of 1.3 million in 2004. The study area has 189 zones, of which 156 zones are internal and 33 zones external, related to the surrounding areas and outside world. These zones are grouped based on socioeconomic characteristics and administrative boundaries into 15 internal regions and region 16 constitutes the external zones. Figure 3 shows the 156 internal zones and the respective 15 regions.

The O/D demand belongs to the design (morning peak) hour of a typical working day in 2006. The transportation system of the study area is comprised of two networks of roads and public transit. The road network has 1078 nodes and 1611 two-way and some one-way links. Figure 4 shows this network. The public transit network is basically that of bus transport with

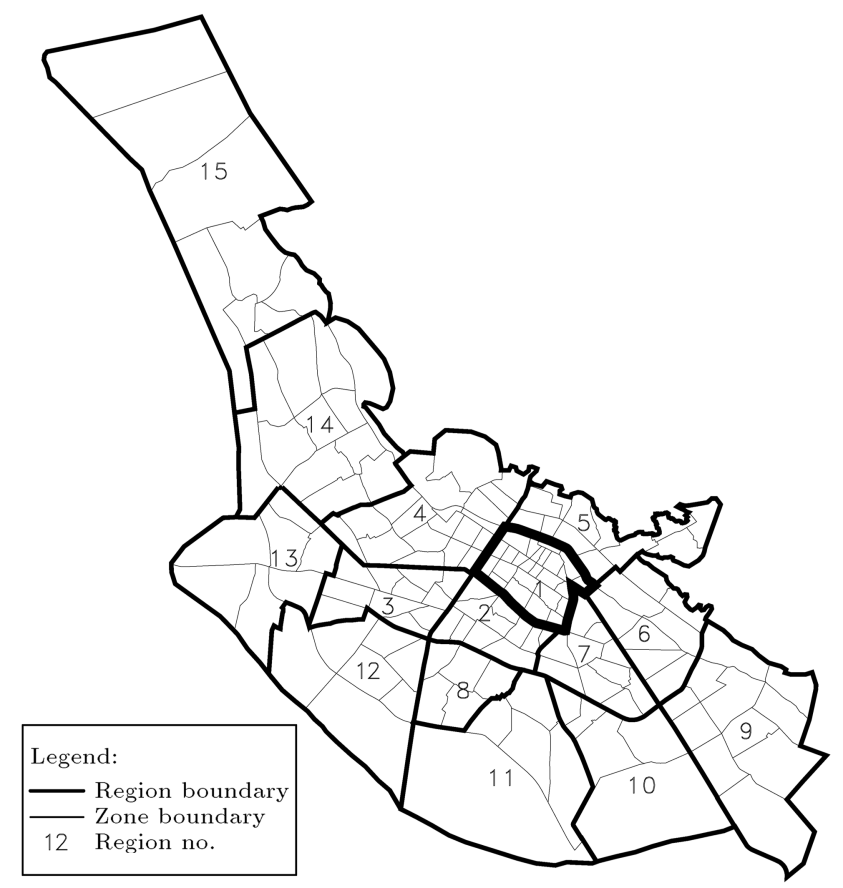

Figure 3. The study area regions (bold lines) and zones (light lines). Region 1 boundary forms the cordon.

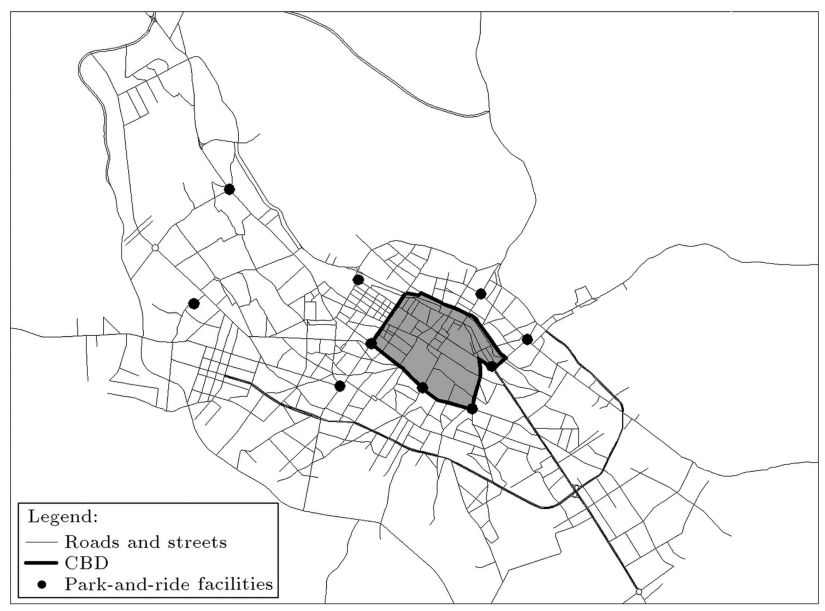

Figure 4. The study network, cordon area, and park-and-ride facility locations (dark dots).

74 bus lines and 382 conventional buses. The street and road network has 17 types of links, with FHWA type of travel time functions (of the form $t=a+b x^{4} ; a$ and $b$ are two link-dependent constants). The signalized intersections have the respective delay function of Webster type and the un-signalized intersections have a delay function of their own. The traffic assignment routines are implemented in EMME/2 environment, as discussed before.

\subsection{The priced area}

The boundary of the area to be priced for the use of private automobiles is assumed to be known. An analysis of the zonal trip attractions, with a parallel analysis of morning peak hour link congestion measure (travel time to free-flow travel time ratio), as well as expert opinion defined the city CBD (zones 1 to 25 , constituting region 1) for this purpose, which has historical characteristics. This area is shown in Figures 3 and 4 .

An independent study [38] defined the 10 parkand-ride bus terminals shown in Figure 4 to facilitate the trips of those passengers who preferred to park at these terminals and use the bus transit systems to reach the central city.

\subsection{Diversion mechanisms}

A key instrument in any pricing systems is a mechanism that is able to foresee the effect of the price level on the decisions of the users. An independent study [32] on the willingness-to-pay of a sample of the users of a central city network resulted in the parameters of the model in Eq. (13), for the different trip purposes, as given in Table 1. $w_{k s}^{p}$ is the percent of total demand that are willing to pay the unit price of $\tau / D_{k s}$, and use the road network by private automobiles. Total demand is measured at zero price level, and the unit price is in terms of units of money per unit O/D distance $\left(D_{k s}\right)$. Superscript $p$ represents the trip purpose, $(k, s)$ the 
Table 1. The estimated parameters of models $w_{k s}^{p}$ in Eq. (13) and $y_{k s}^{p}$ in Eq. (14).

\begin{tabular}{|c|c|c|c|c|}
\hline \multirow[t]{2}{*}{ Trip purpose (p) } & $\boldsymbol{w}_{\boldsymbol{k} s}^{p}=\exp$ & $\left.\left(\frac{\tau}{D_{k s}}\right)^{b}\right]$ & $\boldsymbol{y}_{\boldsymbol{k} s}^{p}=\exp$ & {$\left[c\left(/ \frac{\tau}{D_{k s}}\right)^{d}\right]$} \\
\hline & $a\left(\times 10^{-4}\right)$ & $b$ & $c$ & $d$ \\
\hline Work & -1.629 & 2.057 & -58.994 & -1.086 \\
\hline School & -0.090 & 2.708 & -144.975 & -1.334 \\
\hline Shop & -5.604 & 1.758 & -96.777 & -1.248 \\
\hline Recreation & -1.687 & 2.297 & -162.060 & -1.400 \\
\hline Personal business (and others) & -11.262 & 1.602 & -243.049 & -1.465 \\
\hline Non-home-based & -11.803 & 1.406 & -59.931 & -1.128 \\
\hline
\end{tabular}

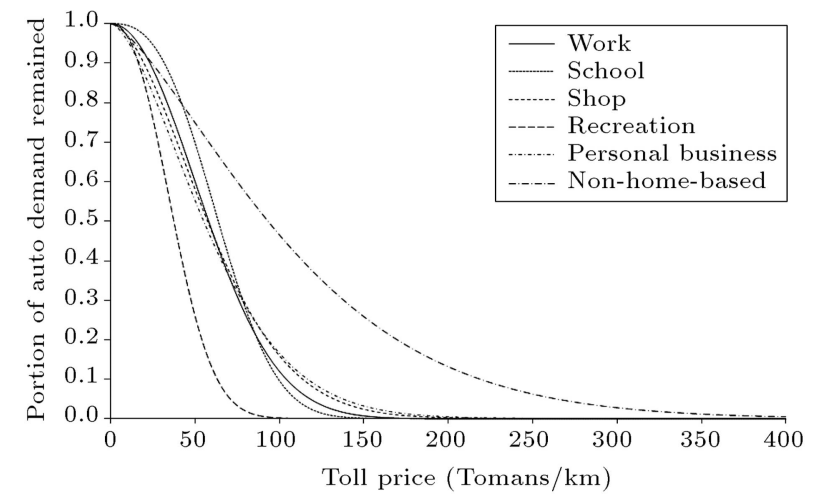

(a) Willingness-to-pay of the auto demand to remain in auto for various trip purposes.

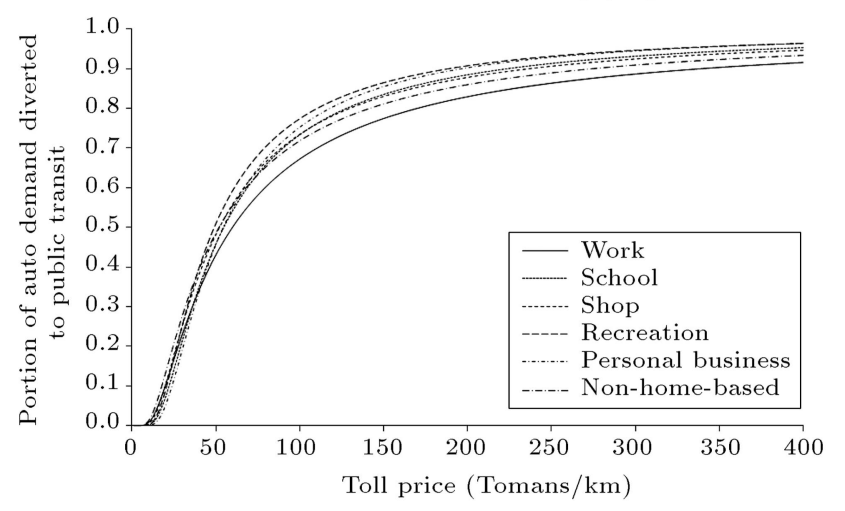

(b) Portion of auto demand diverted to public transit and park-and-ride as a function of toll price for various trip purposes.

Figure 5. Demand diversion models.

$\mathrm{O} / \mathrm{D}$ pair, and $a$ and $b$ are the parameters of the model, calibrated by the observed data. Figure 5(a) shows the pictorial views of the models in Table 1.

Table 1 also shows another set of models shown in Eq. (14), $y_{k s}^{p}$, which is mathematically in the same form of model (13) except that in this case, $c>0$ and $d<0$. For each trip purpose $p$ and $\mathrm{O} / \mathrm{D}$ pair $(k, s)$, this quantity is the portion of the unwilling drivers to pay certain toll levels who are attracted to the public transportation systems. These calibrated models are shown pictorially in Figure 5(b).

To represent the effect of tolls $\tau$ upon the travel costs of the car drivers willing to pay $\tau$ to enter the priced zone, the travel times of all links heading inside the priced zone are increased by the travel time equivalent to the toll:

$$
t_{i j}=t_{i j}+\gamma \tau
$$

where $t_{i j}$ is the average travel time of link $(i, j)$ pointing into the priced zone boundary.

The cost of parking at a $P / R$ bus terminal $(\phi)$ is assumed (for simplicity) to be constant and equal to a fraction $(\alpha)$ of the priced zone entrance fee $(\tau)$ :

$$
\phi=\alpha \tau, \quad 0 \leq \alpha<1 .
$$

The fraction $\alpha$ may depend on the $P / R$ sites based on one or several reasons: value of land of the terminal, proximity to central city, capacity of the parking facilities, etc. This relation of parking fee with the entrance toll helps to more easily understand the effects of these costs upon the auto drivers' decisions. Clearly, one should make sure that $h \phi<\tau$ appreciably for some reasonable hours of parking, $h$.

\subsection{Analysis of variations in parking and entrance fees}

The following experimental results are for short-range demand variation (only mode choice changes). The transportation costs in this study include: (a) private car operating costs; (b) passenger travel time cost of private and public means of transportation; (c) cost of fuel (gasoline and diesel); (d) the cost of the next best choices for the private car passengers; and (e) the cost imposed upon the environment. The cost of decision $k$ regarding the operation costs of the private cars is given in Eq. (15), where $\bar{c}$ is estimated to be 166.7 Tomans of 2006. The monetary value of the travel time for the automobile passengers $\left(C_{t_{a}}^{k}\right)$ and public transport passengers $\left(C_{t_{b}}^{k}\right)$ in Eqs. (16) and (18), respectively, is about $c_{t}=\gamma^{-1}=800$ Tomans $/$ hr.

The cost of fuel may be estimated by the unit cost of the fuel multiplied by the quantity of the fuel consumed in the design hour. The latter quantity is computed for each vehicle type and each link of the network by a function which is dependent on the average speed of the traffic in the link and the fuel consumption rates of particular vehicle types (in 
Table 2. The cost components for various cordon prices, and $\alpha=0.05$ for morning peak hour ( 1 Toman $=10$ Rials).

\begin{tabular}{|c|c|c|c|c|c|c|c|c|c|}
\hline \multirow[b]{2}{*}{$\begin{array}{l}\text { Toll } \\
\text { level }\end{array}$} & \multirow[b]{2}{*}{$\begin{array}{l}\text { Toll } \\
\text { cost } \\
\text { (Rls.) }\end{array}$} & \multirow[b]{2}{*}{$\begin{array}{c}\text { P/R } \\
\text { fee } \\
\text { (Rls./hr) }\end{array}$} & \multicolumn{6}{|c|}{ Cost components (million Rials) } & \multirow[b]{2}{*}{$\begin{array}{c}\text { Total } \\
\text { cost }\end{array}$} \\
\hline & & & Gasoline & Diesel & $\begin{array}{c}\text { Vehicle } \\
\text { operation }\end{array}$ & $\begin{array}{c}\text { Auto } \\
\text { travel } \\
\text { time } \\
\end{array}$ & $\begin{array}{c}\text { Transit } \\
\text { travel } \\
\text { time }\end{array}$ & $\begin{array}{c}\text { Consumers' } \\
\text { surplus } \\
\text { reduction }\end{array}$ & \\
\hline 1 & 0 & 0 & 0 & 0 & 0 & 0 & 0 & 0 & 0 \\
\hline 2 & 5000 & 250 & -1 & 0 & -51 & -6 & 1 & 250 & 193 \\
\hline 3 & 10000 & 500 & -1 & 4 & -126 & -7 & 24 & 453 & 347 \\
\hline 4 & 20000 & 1000 & -12 & 5 & -202 & -15 & 77 & 776 & 629 \\
\hline 5 & 30000 & 1500 & -40 & 6 & -248 & -35 & 103 & 1033 & 819 \\
\hline 6 & 40000 & 2000 & -70 & 7 & -294 & -85 & 125 & 1237 & 920 \\
\hline 7 & 50000 & 2500 & -102 & 7 & -343 & -133 & 144 & 1390 & 963 \\
\hline 8 & 60000 & 3000 & -137 & 12 & -395 & -182 & 152 & 1499 & 949 \\
\hline 9 & 70000 & 3500 & -163 & 13 & -443 & -215 & 163 & 1575 & 930 \\
\hline 10 & 80000 & 4000 & -173 & 13 & -454 & -232 & 176 & 1631 & 961 \\
\hline
\end{tabular}

liter $/ \mathrm{km})$. The prices for gasoline and diesel at the time of this study were 300 and 150 Tomans/liter, respectively.

A sensitivity analysis of the fraction of $\alpha$ in Eq. (32) is performed to investigate the effect of this parameter on the above-mentioned transportation costs. For the alternative policies $k=1$ to 10 corresponding to entrance tolls of 0 (do nothing), $0.5,1,2, \ldots, 8$ thousand Tomans and parking fee fractions of $\alpha=0.00,0.025,0.050,0.100,0.200$, and 1.000 (equivalent to "1.000"), the traffic assignment routine has been run and the transportation system operation characteristics are noted. Figure 6 shows important information in this regard: the demand for $P / R$ facilities shows a better behavior for $\alpha=0.05$. For $\alpha=0$, increase in the entrance toll will increase this demand and for $\alpha=1.0$ (or greater), no one parks at these sites. For interim values of $\alpha$, increase in toll level creates a bell shaped demand level for $P / R$ sites. The value of $\alpha=0.05$ provides $P / R$ demand peak in the middle of reasonable cordon price range, creates a good level of competition between the alternative decisions, and offers acceptable price for the $P / R$ facilities per hour of parking.

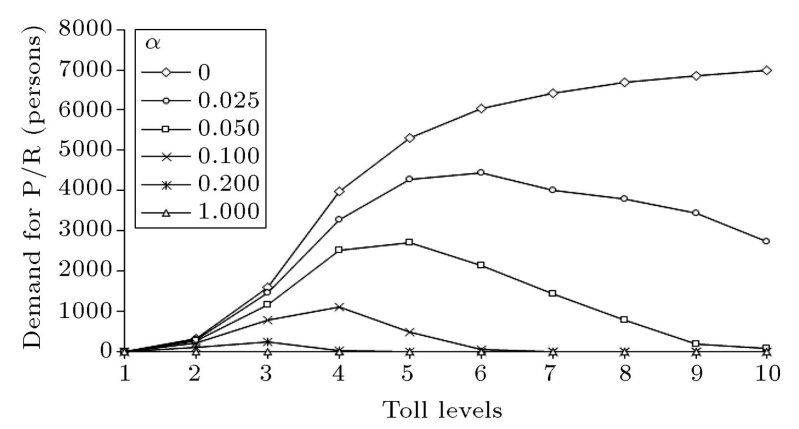

Figure 6. Demand for park-and-ride facilities as a function of $\alpha$.

\section{Traffic assignment results under different toll levels for the short-range case}

The output of the traffic assignment model (Procedures AS and OC) for the case under study for different toll levels would provide the reward matrix for the Markovian decision process and pave the way toward the application of the dynamic cordon pricing (policy iteration) method mentioned at the end of Section 4.1.

Table 2 shows the results of computation of the cost components for $\alpha=0.05$. Figure 7 shows the relative values of the cost components for the transportation system. These values are computed as follows. Let $Z^{i}$ be the cost component $Z$ (for example, gasoline cost) for the toll price $i$ (=1 to 10), where toll level 1 is equal to zero (the do-nothing alternative). Let $D Z^{i}=Z^{i}-Z^{1}$. Normalize the values of $D Z^{i}$ by dividing them by the respective maximum (minimum) values over $i, D Z^{i} / \operatorname{Ext}_{i} D Z^{j}$, where $\operatorname{Ex}_{j} t=$ $\operatorname{Max}_{j}\left(\operatorname{Min}_{j}\right)$ depending on whether $Z$ is a cost which

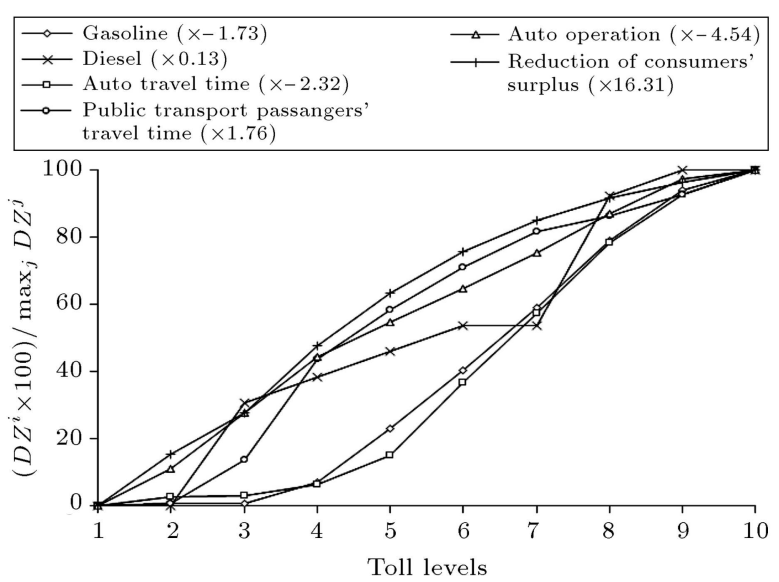

Figure 7. Variation of the cost components of the total cost of the network. 


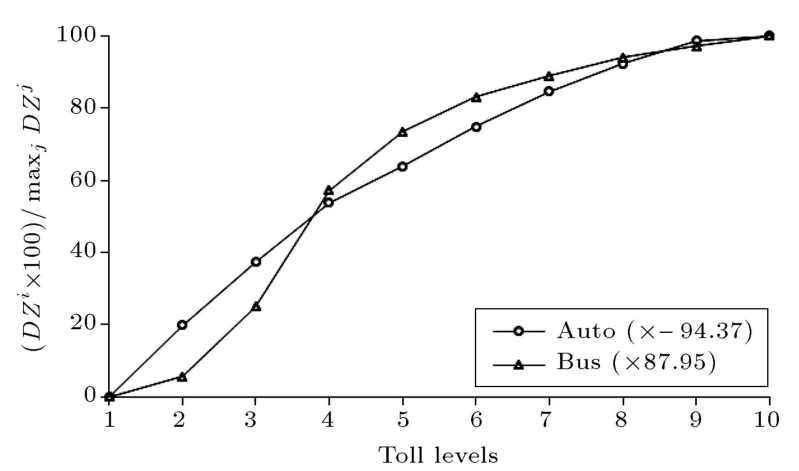

Figure 8. Variation of modal trips by toll increase.

increases (decreases) with the increase of the toll (for example, diesel (gasoline) cost with $\left.D Z^{i}>(<) 0\right)$. The general trends of variation of the cost components of the system are shown in Figure 7 , which are s-shaped with respect to the increase in toll level. The same trends exist for other operating characteristics of the system as well, as shown in Figure 8, for the auto and bus passenger trips. These types of variation are in agreement with our general feeling that there are limits to any changes.

\section{Optimal strategies for cordon pricing for the short-range case}

We are, now, in a position to run the proposed dynamic pricing model to find the optimal strategies for the ambient air pollution control for the city under study. We do this, first, by unifying the decision outcomes under a given weighting scheme for the different bodies involved to get the reward matrix. Then, we show how the decision would change if these weighting schemes and the surrounding forces (seasons) change.

Any toll level $k$ will change the state of the system from $i$ to $j$ and such changes continue over time particularly with the influence of externalities such as atmospheric conditions. Change of state $i$ to state $j$ in the system, in a period of time (say, a day), due to decision $k$, results in a reward of $R^{k}(i, j)$. In what follows we define an example for demonstration purposes.

We assume the outcome of the decision $k$ in the reward function to be attributed to two major interest groups. Each outcome has an importance, or weight, that we show by $\omega$ :

(a) The operator outcomes (including changes in the consumption of the limited resources of gasoline and diesel fuels, $G^{k}$ and $D^{k}$, respectively) with weight $\omega_{r e}$, and

(b) The public outcomes with weight $\omega_{p}=1-\omega_{r e}$.

The public outcomes may, in turn, be classified into two subgroups:

(b.1) The general public outcomes (including the changes in the public health effects) in state $j, H^{j}$ with weight $\omega_{p h}$, and

(b.2) The users of the network outcomes with weight $\omega_{u}$.

The latter may be divided into two new categories:

(b.2.1) The yearly operation cost, which includes the distance traversed by the automobiles in the network (proportional to the monetary cost of travel), $V k^{k}$; the travel time spent by the public vehicle passengers, $T p^{k}$; and the travel time spent by the nonpublic vehicle passengers, $T n p^{k}$; all with weight $\omega_{u o}$, and

(b.2.2.) The reduction in the welfare of the automobile occupants, $C S^{k}$, which may be interpreted as users' capital cost, considered with weight $\omega_{u c}$.

$$
\begin{aligned}
R^{k}(i, j)= & \omega_{r e} \cdot\left(G^{k}+D^{k}\right)+\omega_{p h} \cdot\left(H^{j}\right) \\
& +\omega_{u o \cdot} \cdot\left(V k^{k}+T p^{k}+T n p^{k}\right) \\
& +\omega_{u c} \cdot\left(C S^{k}\right) .
\end{aligned}
$$

All policy/state-related variables are scaled in the range of $[0,1]$ for clear reasons.

To run the model, we need some input data. Table 3 shows the values for $w_{j}, a_{i}$, and $b_{i}$ in Eqs. (27) and (30) for 3 seasons of the year. (There was no observation for summer.)

The policy iteration method of Howard [31] has been run for various values of $\omega_{r e}\left(\right.$ or $\left.\omega_{p}\right)$. In each case, the value of $\omega_{p h}$ is increased gradually from 0.00 to some appropriate value to see some notable differences in the results. These results are summarized in Table 4 for various values of $\omega_{r e}$. This table, also, shows the optimal policies for the three seasons, for various values of $\omega_{r e}$ and $\omega_{p h}$ (and therefore, $\omega_{u}$ ) levels, to show how the optimal decisions change. Figure 9

Table 3. Values of $w_{j}$ 's in Eqs. (30), and $a_{i}$ 's and $b_{i}$ 's in Eqs. (28).

\begin{tabular}{cccccccccc}
\hline & \multicolumn{3}{c}{ Spring } & \multicolumn{3}{c}{ Autumn } & \multicolumn{3}{c}{ Winter } \\
\hline$j$ & 1 & 2 & 3 & 1 & 2 & 3 & 1 & 2 & 3 \\
$w_{j}$ & 0.63 & 0.32 & 0.05 & 0.55 & 0.39 & 0.06 & 0.74 & 0.33 & 0.03 \\
\hline \multicolumn{3}{c}{$a_{1}=1.86 E-06, a_{2}=7.74 E-05, b_{1}=0.9, b_{2}=-0.005$ for all seasons. } \\
\hline
\end{tabular}


Table 4. Toll price level for different cost component weights, air quality states, and seasons*.

\begin{tabular}{|c|c|c|c|c|c|c|c|c|c|c|c|c|}
\hline \multicolumn{4}{|c|}{ Weight } & \multicolumn{9}{|c|}{ Season } \\
\hline \multirow{2}{*}{$\omega_{r e}$} & \multirow{2}{*}{$\omega_{p h}$} & \multicolumn{2}{|c|}{$\omega_{u}$} & \multicolumn{3}{|c|}{ Winter } & \multicolumn{3}{|c|}{ Autumn } & \multicolumn{3}{|c|}{ Spring } \\
\hline & & $\omega_{u o}$ & $\omega_{c s}$ & $i=1$ & $i=2$ & $i=3$ & $i=1$ & $i=2$ & $i=3$ & $i=1$ & $i=2$ & $i=3$ \\
\hline 0.50 & 0.00 & 0.13 & 0.38 & 2 & 2 & 2 & 2 & 2 & 2 & 2 & 2 & 2 \\
\hline 0.41 & 0.18 & 0.10 & 0.31 & 2 & 7 & 2 & 2 & 2 & 2 & 2 & 7 & 2 \\
\hline 0.41 & 0.19 & 0.10 & 0.30 & 2 & 7 & 2 & 2 & 7 & 2 & 2 & 7 & 2 \\
\hline 0.39 & 0.22 & 0.10 & 0.29 & 2 & 9 & 2 & 2 & 7 & 2 & 2 & 7 & 2 \\
\hline 0.39 & 0.23 & 0.10 & 0.29 & 2 & 9 & 2 & 2 & 7 & 2 & 2 & 9 & 2 \\
\hline 0.38 & 0.24 & 0.10 & 0.29 & 2 & 9 & 2 & 2 & 7 & 7 & 2 & 9 & 2 \\
\hline 0.38 & 0.25 & 0.09 & 0.28 & 7 & 9 & 7 & 2 & 9 & 7 & 2 & 9 & 7 \\
\hline 0.37 & 0.27 & 0.09 & 0.27 & 7 & 9 & 7 & 2 & 9 & 7 & 7 & 9 & 7 \\
\hline 0.34 & 0.32 & 0.09 & 0.26 & 7 & 9 & 7 & 7 & 9 & 7 & 7 & 9 & 7 \\
\hline 0.30 & 0.40 & 0.08 & 0.23 & 9 & 9 & 7 & 7 & 9 & 7 & 7 & 9 & 7 \\
\hline 0.29 & 0.43 & 0.07 & 0.21 & 9 & 10 & 7 & 7 & 9 & 7 & 7 & 9 & 7 \\
\hline 0.28 & 0.44 & 0.07 & 0.21 & 9 & 10 & 7 & 7 & 9 & 7 & 9 & 9 & 7 \\
\hline 0.27 & 0.47 & 0.07 & 0.20 & 9 & 10 & 10 & 7 & 9 & 7 & 9 & 10 & 7 \\
\hline 0.25 & 0.50 & 0.06 & 0.19 & 9 & 10 & 10 & 7 & 9 & 7 & 9 & 10 & 10 \\
\hline 0.25 & 0.51 & 0.06 & 0.18 & 9 & 10 & 10 & 9 & 9 & 7 & 9 & 10 & 10 \\
\hline 0.24 & 0.52 & 0.06 & 0.18 & 9 & 10 & 10 & 9 & 9 & 10 & 9 & 10 & 10 \\
\hline 0.23 & 0.55 & 0.06 & 0.17 & 9 & 10 & 10 & 9 & 10 & 10 & 9 & 10 & 10 \\
\hline 0.16 & 0.68 & 0.04 & 0.12 & 10 & 10 & 10 & 9 & 10 & 10 & 9 & 10 & 10 \\
\hline 0.14 & 0.72 & 0.04 & 0.11 & 10 & 10 & 10 & 9 & 10 & 10 & 10 & 10 & 10 \\
\hline 0.11 & 0.79 & 0.03 & 0.08 & 10 & 10 & 10 & 10 & 10 & 10 & 10 & 10 & 10 \\
\hline
\end{tabular}

$*_{i}=1,2$, and $3 \equiv$ healthy, tolerable, and harmful ambient air quality states.

$\omega_{j}=$ weight/importance of outcome $j=r e$ (resources used), $p h$ (public health), $u$ (user-related),

uo (user operation costs), and $u c$ (user surplus reduction).

shows these results pictorially for a range of values for $\omega_{r e}(=0.00,0.25,0.50,0.75,1.00)$ and the three states $(i=1,2$, and 3$)$. For each combination of the values of these two parameters, the optimal policy, or toll level $\left(k^{*}=1,2, \ldots, 10\right)$ has been found for each of the three seasons (spring, autumn, and winter) for the range of $\omega_{p h}(0.00$ to 1.00$)$. The following conclusions may be drawn from the 15 figure cells $\left(i, \omega_{r e}\right)$ of Figure 9:

a. Increase in $\omega_{p h}$ (weight of public health effects) results in higher tolls;

b. If the environmental quality is high $(i=1)$, the optimal policy suggests lower tolls to minimize the cost levied on the car passengers, unless $\omega_{p h}$ is high;

c. When environmental quality reaches a lower level $(i=2)$, the optimal policy suggests higher tolls in much lower values of $\omega_{p h}$ to prevent the incident of lower quality environment $(i=3)$;

d. For unhealthy environmental quality $(i=3)$, lower toll levels are optimal to prevent higher cost of consumer surplus together with higher environmental cost, unless $\omega_{p h}$ is high to suggest higher tolls; e. These policies are different for different seasons (with different probabilities and intensities of wind and precipitations). In winter, with higher inversion cases, higher tolls are suggested for lower $\omega_{p h}$ 's. This happens in spring in higher $\omega_{p h}$. In autumn, when the probability and intensity of wind increase, to take more strict actions (higher tolls), one requires higher $\omega_{p h}$.

\section{Summary and conclusions}

Consider a city that faces potential air pollution problem from mobile sources. The congested zones of the city network are encircled by cordons which are priced for private car use entering these zones, to encourage these car drivers to use public modes of transportation. There are several park-and-ride facilities around the zonal boundaries, which are also priced differently. The prices are in increments, which may be chosen based on the level of pollution in the city. This paper presents a model to help the city government to dynamically decide on the price of using the network facilities in the congested zones, to curb the pollution level 

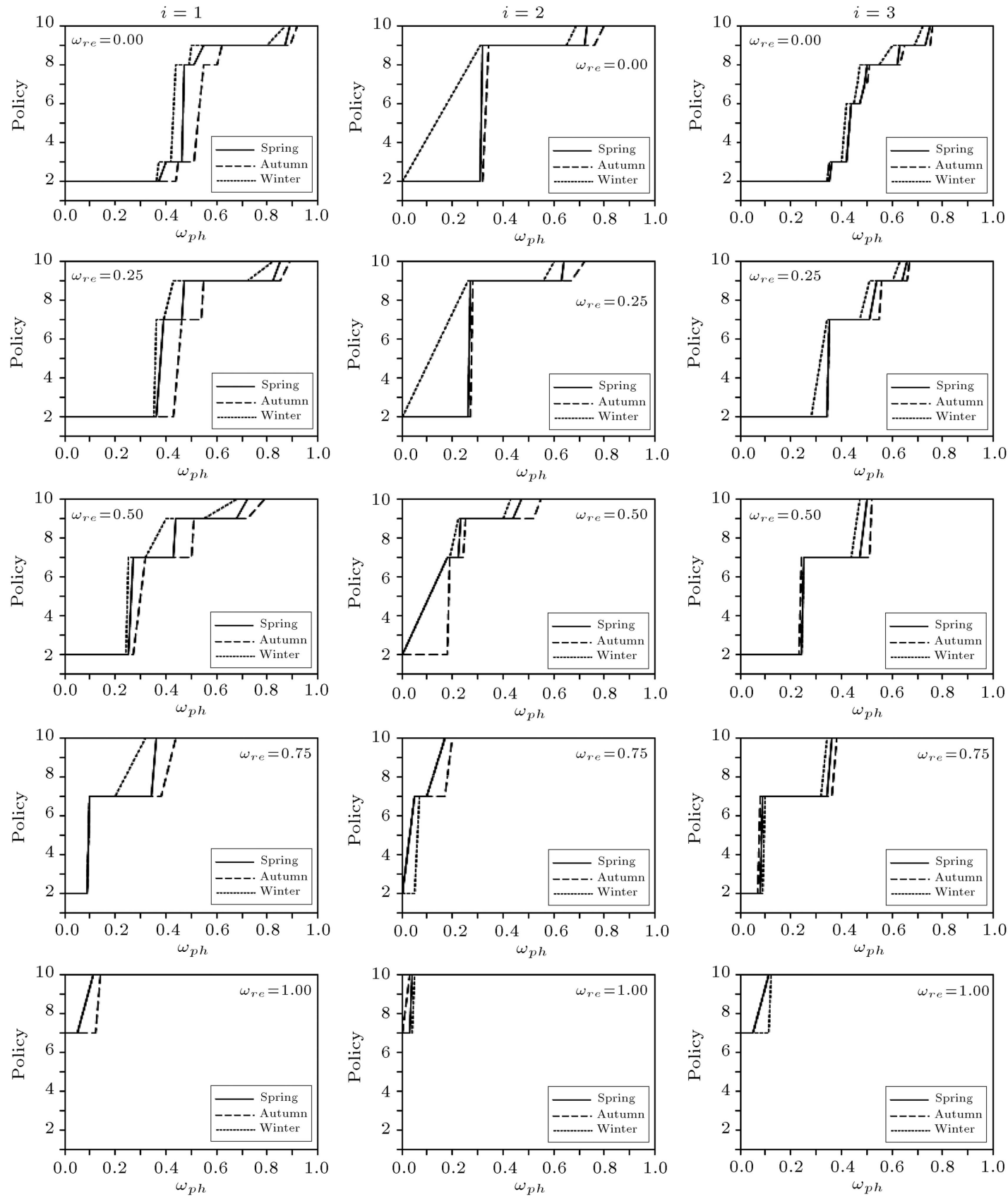

Figure 9. Pictorial representations of optimal toll levels for different public health weights $\left(\omega_{p h}\right)$ and different pairs of resource weight $\left(\omega_{r e}\right)$ and air quality level $(i)$ for the three seasons under consideration.

such that the long-run net benefit of the decisions is optimized.

Ambient air pollution is detected by (for example) Lidar. Weather condition (wind speed, etc.) is known by past data for each season. Depending on the weather condition, pollution level changes. Hence, price levels of entering a cordon and parking at the park-andride facilities for tomorrow are determined based on these factors. The public are informed about these prices the day/night before by variable signs at suitable places, internet, automatic communication system, etc.
The problem is formulated as a Markovian decision-making problem in which the state space is the quality of the ambient air in the city. The transition matrix depends on the network flow which affects it negatively and the weather condition (wind) of next day which may affect it positively. The background probabilities of state space transition depend on the season. The reward matrix takes into account user travel time costs, private vehicle operating costs, fuel costs, and the cost imposed upon the private car passengers to choose their next best options, as well as the cost imposed on the environment by air pollution. 
The purpose of the model is to help contain the latter part of the total cost (that is, the air pollution cost to environment) by appropriate cordon and park-andride pricing. These cost items are computed by an integrated transportation demand and multi-class flow model. Optimal long-run pricing decisions are found by policy iteration method of Howard [31], which determines tomorrow's optimal prices of cordon and parking facilities for the operator of the system when the operator determines today's (end of day) ambient air quality level.

The model has been applied to a real network and the results have been discussed and summarized at the end of the previous section of this paper.

Fruitful future research directions may include the following: (a) Real-day decision making by real-time weather forecast (instead of seasonal weather forecast for a steady-state condition); (b) inclusion of time-ofday flexibility and elasticity of demand in the problem; and (c) inclusion of longer-run user decisions, such as trip production, in the process.

\section{Acknowledgement}

The authors would like to thank the anonymous referees for their helpful comments that have enhanced the presentation of the paper. The authors of the paper, however, are responsible for its content.

\section{References}

1. Lewis, N.C. "Road pricing theory and practice", Thomas Telford Services, Ltd., London (1994).

2. Small, K.A., Worldwide Experience with Congestion Pricing, San Diego State University Foundation, Dpt. of Civil and Environmental Engineering (1997).

3. Babazadeh, A., Traffic Control to Reduce Air Pollution, MS Thesis, Civil Eng. Dept., Sharif University of Technology, Tehran, Iran (1997).

4. Aghababazadeh, B. "Urban traffic control to reduce air pollution by network pricing", MS Thesis, Civil Eng. Dept., Sharif University of Technology, Tehran, Iran (2006).

5. Amirgholy, M., Rezaeestakhruie, H. and Poorzahedy, H. "Multi-objective cordon price design to control long run adverse traffic effects in large urban areas", NETNOMICS: Economic Research and Electronic Networking, pp. 1-52 (2015).

6. Tsekeris, T. and Vo $\beta$, S. "Design and evaluation of road pricing: state-of-the-art and methodological advances", Netnomics, 10(1), pp. 5-52 (2009).

7. Khazzoom, J.D. "The impact of a gasoline tax on auto exhaust emissions", Journal of Policy Analysis and Management, 10(3), pp. 434-454 (1991).

8. Shefer, D. "Congestion, air pollution, and road fatali- ties in urban areas", Accident Analysis \& Prevention, 26(4), pp. 501-509 (1994).

9. Otterström, T. "Pricing of environmental impacts of emissions from road traffic-recent and present research in Finland", Science of the Total Environment, 169(1), pp. 311-319 (1995).

10. Chin, A.T. "Containing air pollution and traffic congestion: transport policy and the environment in Singapore", Atmospheric Environment, 30(5), pp. 787801 (1996).

11. Joumard, R., Lamure, C., Lambert, J. and Tripiana, F. "Air quality and urban space management", Science of the Total Environment, 189, pp. 57-67 (1996).

12. Proost, S. and Van Dender, K. "The welfare impacts of alternative policies to address atmospheric pollution in urban road transport", Regional Science and Urban Economics, 31(4), pp. 383-411 (2001).

13. Beevers, S.D. and Carslaw, D.C. "The impact of congestion charging on vehicle emissions in London", Atmospheric Environment, 39(1), pp. 1-5 (2005).

14. Mitchell, G. "Forecasting environmental equity: air quality responses to road user charging in Leeds, UK", Journal of Environmental Management, 77(3), pp. 212-226 (2005).

15. Mitchell, G., Namdeo, A. and Milne, D. "The air quality impact of cordon and distance based road user charging: An empirical study of Leeds, UK", Atmospheric Environment, 39(33), pp. 6231-6242 (2005).

16. Schuitema, G., Linda, S. and Charles, V. "Are pricing policies effective to change car use?", IATSS Research, 31(1), pp. 21-31 (2007).

17. Dai, H., Yao, E. and Zhao, R. "Research on congestion pricing in multimode traffic considering delay and emission", Discrete Dynamics in Nature and Society (2015).

18. Lyons, T.J., Kenworthy, J.R., Moy, C. and dos Santos, F. "An international urban air pollution model for the transportation sector", Transportation Research Part D: Transport and Environment, 8(3), pp. 159-167 (2003).

19. Leeves, G.D. and Herbert, R.D. "Economic and environmental impacts of pollution control in a system of environment and economic interdependence", Chaos, Solitons \& Fractals, 13(4), pp. 693-700 (2002).

20. de Palma, A. and Lindsey, R. "Traffic congestion pricing methodologies and technologies", Transportation Research Part C: Emerging Technologies, 19(6), pp. 1377-1399 (2011).

21. May, A.D., Liu, R., Shepherd, S.P. and Sumalee, A. "The impact of cordon design on the performance of road pricing schemes", Transport Policy, 9(3), pp. 209220 (2002).

22. Sumalee, A. "Optimal toll ring design with spatial equity impact constraint: An evolutionary approach", Journal of Eastern Asia Society for Transportation Studies, 5, pp. 1813-1828 (2003). 
23. Sumalee, A. "Optimal road user charging cordon design: a heuristic optimization approach", ComputerAided Civil and Infrastructure Engineering, 19(5), pp. 377-392 (2004).

24. Zhang, X. and Yang, H. "The optimal cordon-based network congestion pricing problem", Transportation Research Part B: Methodological, 38(6), pp. 517-537 (2004).

25. Mun, S.-I., Konishi, K.-J. and Yoshikawa, K. "Optimal cordon pricing", Journal of Urban Economics, 54(1), pp. 21-38 (2003).

26. Mun, S.-I., Konishi, K.-J. and Yoshikawa, K. "Optimal cordon pricing in a non-monocentric city", Transportation Research Part A: Policy and Practice, 39(7), pp. 723-736 (2005).

27. Ho, H.W., Wong, S.C., Yang, H. and Loo, B.P.Y. "Cordon-based congestion pricing in a continuum traffic equilibrium system", Transportation Research Part A: Policy and Practice, 39(7), pp. 813-834 (2005).

28. Eliasson, J., Haltkranz, L., Nerhagen, L. and Rosqvist, L.S. "The Stockholm congestion-charging trial 2006: Overview of effects", Transportation Research Part A: Policy and Practice, 43(3), pp. 240-250 (2009).

29. Expert Group Summary, Available at: http://www. stockholmsforsoket.se. Expert Group Includes Algers, S., Freij, K.B., Eliasson, J., Henricksson, C., Hultkrantz, L., Ljungberg, C., Nerhagen, L. and Rosqvist, L.S. [Accessed Dec. 2014] (2014).

30. Walker, J. "The acceptability of road pricing", Royal Automobile Club (RAC) Foundation for Motoring., London (2011).

31. Howard, R.A. "Dynamic programming and Markov processes", Research Report by MIT Press and JohnWiley and Sons, Inc., New York (1960).

32. ITSR "The proposed coordinated taxi in the overall public transportation system for the City of Mashhad", Institute for Transportation Studies and Research, Mashhad Comprehensive Transportation Studies, Report No. 82-05, Sharif University of Technology, Tehran (in Farsi) (2003).

33. Atel, N.R. "A Markov process model for dynamic control of emissions", New Concepts in Air Pollution Research Springer, pp. 159-167 (1974).

34. ITSR "The traffic assignment model for the City of Shiraz and the performance of the network in this city", Institute for Transportation Studies and Research, Shiraz Comprehensive Transportation Studies, Report No. 79-17, Sharif University of Technology, Tehran (in Farsi) (2000).

35. Spiess, H. and Florian, M. "Optimal strategies: a new assignment model for transit networks", Transportation Research Part B: Methodological, 23(2), pp. 83102 (1989).

36. Sheffi, Y., Urban Transportation Networks: Equilibrium Analysis with Mathematical Programming Methods, Prentice-Hall, Englewood Cliffs, NJ (1985).
37. "EMME/2 user's manual", INRO consultants Inc., Montreal, Canada (1999).

38. ITSR "The proposed bus transportation system for the City of Shiraz", Institute for Transportation Studies and Research, Shiraz Comprehensive Transportation Studies, Report No. 80-08, Sharif University of Technology, Tehran (in Farsi) (2001).

\section{Appendix A}

\section{The transition probability matrix}

Suppose there is no weather influence upon the ambient air and assume life time of state $i, T_{i}$, is distributed as negative exponential, as in Eq. (22), with mean and variance:

$$
E\left[T_{i}\right]=\theta_{i}^{-1}, \quad \operatorname{Var}\left[T_{i}\right]=\theta_{i}^{-2} .
$$

Then, after any time unit (stage), any state (of air quality) will either remain the same or turn into another worse condition. The transition probability of the state of the system turning from $i$ to $j, j \geq i$, under decision $k, p^{k}(i, j)$, may be computed as shown below:

$$
\begin{aligned}
p(1,1) & =\operatorname{Pr}\left\{T_{1}>1\right\}=e^{-\theta_{1}}, \\
p(1,2) & =\operatorname{Pr}\left\{T_{1}+T_{2}>1 \mid T_{1} \leq 1\right\} \\
& =\frac{1}{\theta_{2}-\theta_{1}}\left(e^{-\theta_{1}}-e^{-\theta_{2}}\right), \\
p(1,3) & =1-p(1,1)-p(1,2), \\
p(2,2) & =\operatorname{Pr}\left\{T_{2}>1\right\}=e^{-\theta_{2}}, \\
p(2,3) & =1-p(2,2), \\
p(3,3) & =1 .
\end{aligned}
$$

Note that $p(i, j)=0$, for $i>j, i, j=1,2,3$.

Replace $\theta_{i}^{\prime} \mathrm{s}$ in Eqs. (A.2) by the corresponding expressions in Eq. (26) to get what are given in Eqs. (28).

\section{Appendix $B$}

The flowcharts of the proposed model

(a) The flowchart for the Markovian decision-making model (Procedure HP) (Figure B.1).

(b) The flowchart for the reward computation procedure (Procedure AS and Procedure OC) (Figure B.2).

$T_{k s}^{p m}(\tau)$ is total trips from origin $k$ to destination $s$ by mode $m$ for trip purpose $p$ when toll price is $\tau$ for the cordon; $O$ is set of zones outside cordon (including $P / R$ zones); $I$ is set of zones inside cordon; $m \in M$ is 


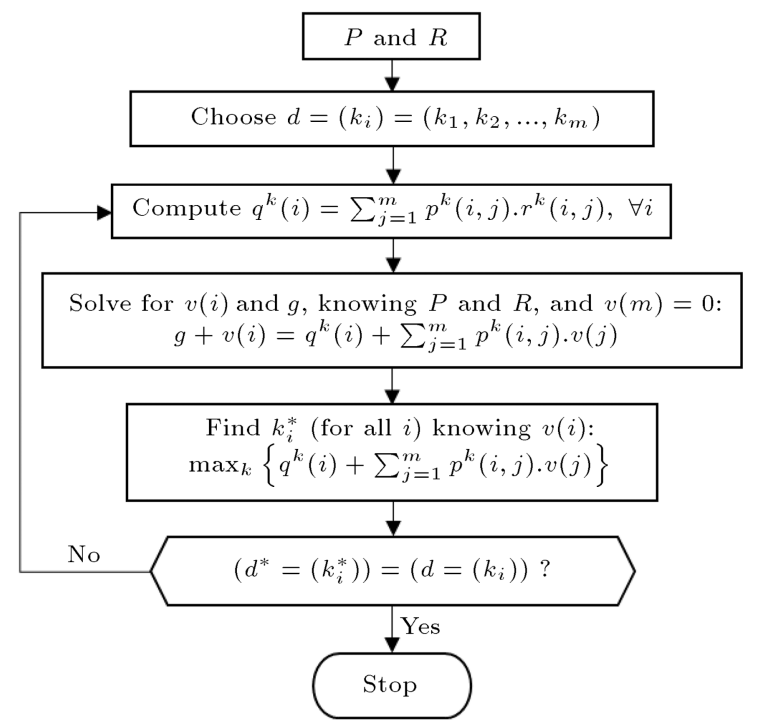

Figure B.1. The flowchart for the Markovian decisionmaking model (Procedure HP). \{auto $(a)$, bus $(b)$, taxi $(t)$, and others $(o)$ including several other modes $\} ; p$ is trip purpose; and $\sim$ $(x x)$ next to different relations represent the equation numbers in the text (to build relations with the discussions in the manuscript);

(c) The flowchart for the transition probability computation (Procedure TP) (Figure B.3).

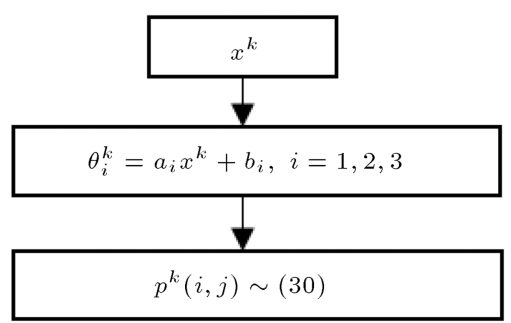

Figure B.3. The flowchart for the transition probability computation (Procedure TP).

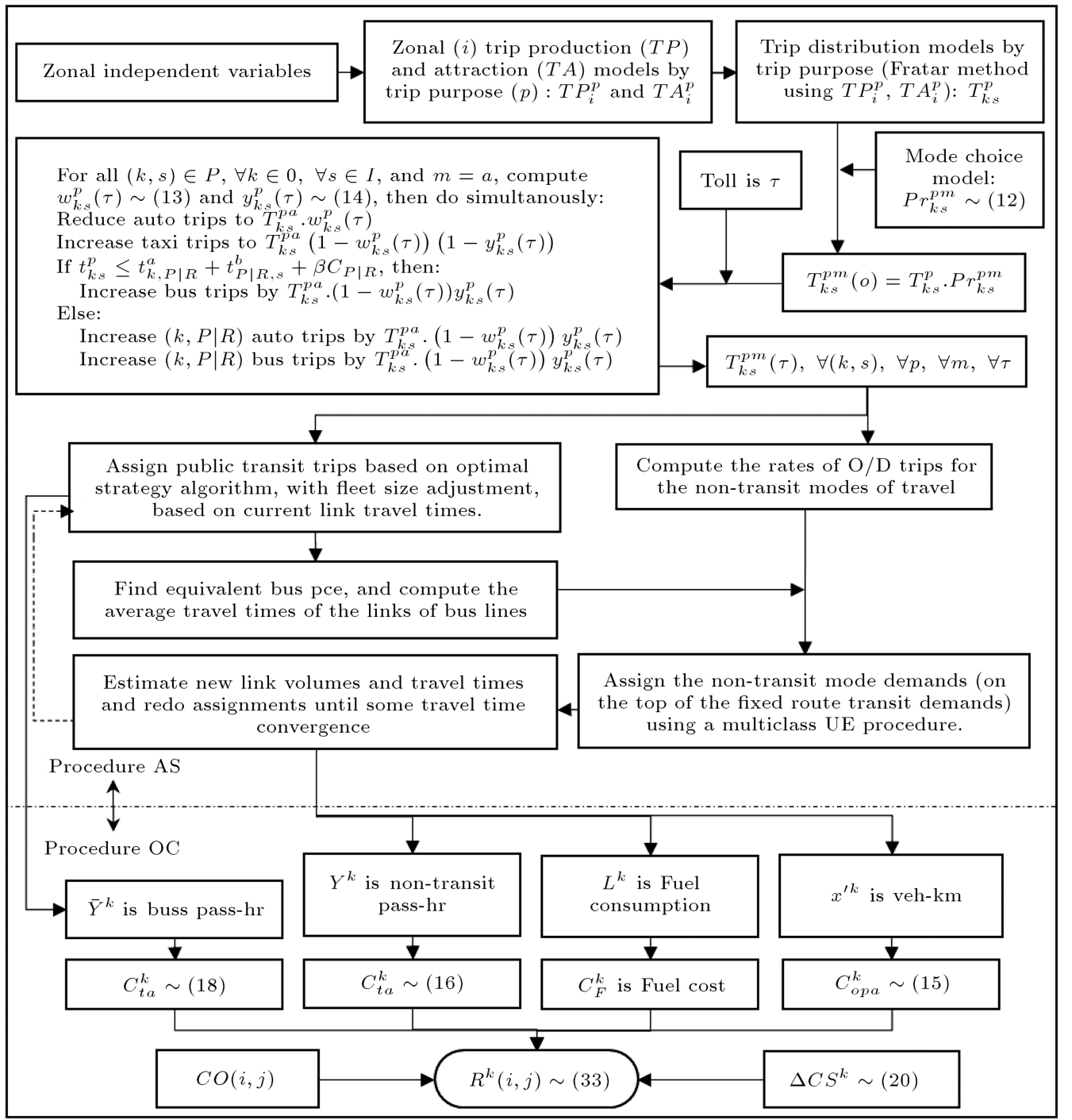

Figure B.2. The flowchart for the reward computation procedure (Procedure AS and Procedure OC). 


\section{Biographies}

Hossain Poorzahedy is Professor of Transportation at Sharif University of Technology, Department of Civil Engineering. He received his PhD from Northwestern University (1980), MS from Stanford University (1976), and BS from Shiraz University (1975). His life-long interest has been in various aspects of transportation network design (solution methods; large real network case studies; network reliability, capacity, sustainability, resiliency, and chaotic behavior; network pricing; and network development finance through buildoperate-transfer schemes). His recent works bring together land use-transportation interaction, transitoriented development, and disaster management as related to transportation.

Babak Aghababazadeh received his MS from Sharif University of Technology in Transportation Engineer- ing and Planning in 2005. His experience is focused on the economic evaluation and feasibility studies of transportation projects for the Ministry of Transportation and Urban Development and the related organizations, as well as for large metropolitan areas. His interest and recent works were in the area of transportation network design, traffic impact studies, and privatization and business plan in transportation industry.

Abbas Babazadeh obtained his PhD in Transportation Engineering and Planning from the Department of Civil Engineering, Sharif University of Technology, Iran. He is currently an Assistant Professor in the School of Civil Engineering, University of Tehran, Iran. His research interests include modeling and analysis of complex transportation systems, and mostly traffic assignment problem. He has been involved in several urban transportation planning and port planning projects in Iran. 